\title{
Piloting a new approach: \\ making use of technology to present a distance learning computer science course
}

\author{
Tina Wilson and Denise Whitelock \\ Institute of Educational Technology, The Open University
}

Computer-Mediated Communication (CMC) systems have been described and evaluated in a number of ways by different researchers in the field. This paper proposes that computer conferencing systems should be designed to encourage students to participate in three dimensions previously treated by separate researchers. These can be summarized as a knowledge dimension, a social dimension and a motivational dimension. This paper reports on how one particular conference, that of M205-STILE, was constructed to take account of these dimensions and to facilitate students' computer-supported cooperative learning.

\section{Introduction}

Teaching projects which make use of new technology are becoming of interest to all academic institutions in the UK due to economic pressure to increase student numbers. CMC (ComputerMediated Communication) such as computer conferencing appears an attractive solution to higher education's 'numbers' problem, with the added benefit that it is free from time and place constraints. Researchers have discussed CMC from a number of different perspectives, for example Mason and Kaye (1989) describe a CMC system as a system of interactivity between tutors, students, resources and organizational structure. Steeples et al (1993) consider CMC in terms of group cohesion, modes of discourse and intervention strategies to stimulate and structure participation. Goodyear et al (1994) discuss the Just in Time (TT-Based) Open Learning (JTTOL) model in terms of a set of educational beliefs, role definitions, working methods and learning resources, together with a definition of infrastructure requirements for CMC. Shedletsky (1993) suggests that a CMC should be viewed in terms of an intrapersonal communication' model, while Mayes et al (1994) identify three types of learning which is mediated by telematics, that is, learning by conceptualization, construction and dialogue. Other researchers, such as Velayo (1994), describe the teacher as 'an active agent', and present a model for computer conferencing which neglects the social aspect of CMC, while Berge (1995) mentions the importance of social activity between students and the importance of the 
role of the moderator. From these accounts, there appear to be a number of dimensions which can be used to evaluate CMC. Not all researchers emphasize the same dimensions; however, this paper proposes that computer conferencing systems should be designed to encourage students to participate in all three of the following dimensions. These can be summarized as:

(a) a knowledge dimension (includes domain and meta knowledge);

(b) a social dimension; and

(c) a motivational dimension.

We will focus on the design and management of a conference M205-STILE, which was employed by the Open University's Computer Science department to supplement the teaching of an undergraduate course. The conference was structured into sub-conferences to take account of the above three dimensions and to facilitate students' computer-supported collaborative learning. This paper reports on the construction of the CMC environment, but more importantly how the three dimensions can be sustained through the role of a person whom we have called an Interactive Media Facilitator (IMF). This implementation is part of the 'Students' and Teachers' Integrated Learning Environment' (STILE) project.

\section{The STILE project}

The STILE project started at the Open University at the end of March 1994, and set out to pilot the use of conferencing facilities on M205, the Fundamentals of Computing course. The main aim of the project was to improve the presentation of the course by offering online facilities to a group of 110 students taking the course in 1995 (February to November). M205 usually has a student population of over 3,000, and is presented to the Open University's distance learners as text and video material. For the students taking part in the project, the extra commitment was to use the online facilities for 'tutorial-type support', to access extra course materials, and to interact with their tutor and fellow students. The students who took part were selected from volunteers who were interested in participating, had suitable equipment, for example a 386 PC to a particular specification, a telephone line, and were prepared to pay their own telephone bill. For further information on the selection of tutors and students see Wilson (1995).

\section{The M205-STILE computer conference}

Over 100 students used Softarc's FirstClass conferencing system to engage with their fellow students and tutors. Sub-conferences were set up at various levels within M205-STILE where the students could socialize, work in tutorial groups, consult with the course team, and access extra course material (see Figure 1). It is even at a first glance obvious to see how the social and knowledge dimensions of the conference have been catered for. The Tutorial conferences and the Help conference provide the knowledge dimensions, while the general Meeting Area and the Student Only area provide the social dimension. This paper concentrates on the Help and Meeting Place conferences. We anticipated that the motivational aspects of the conferencing system would become evident through the changing nature of the conference itself, and that the introduction of an independent IMF would have a significant contribution to the motivational aspects of the conferences overall. 


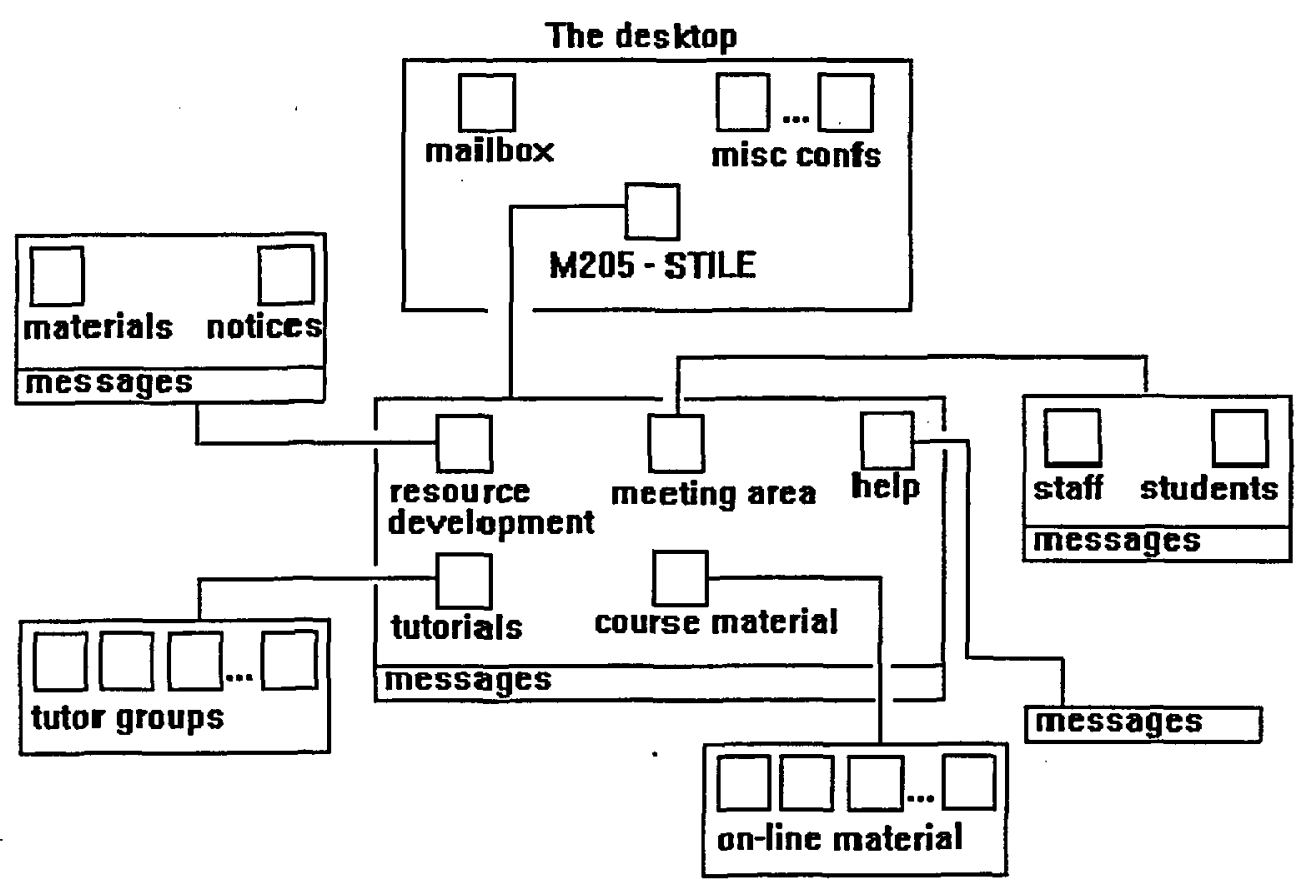

Figure 1: Conference structure for M205-STILE

\section{The role of the Interactive Media Facilitator}

In order to create a learning environment for the students without overloading the tutors, it was important to consider how to minimize the perceived workload. Goodyear et al (1991) found that tutoring via email worked well but that the 'quality and quantity of interactions on matters of course content' did not meet initial expectations. To ensure a work focus, the overall control and responsibility for all conferences within M205-STLE was allocated to an independent controller, the IMF. With this strategy, the tutors were left free to engage in the tutorial conferences and to dip into the other conferences as they wished. In order to reduce tutoroverload associated with reading social-type messages, the work-related dialogue was separated from chat, not only by creating separate conferences but also giving the responsibility of the chat conferences to the IMF.

There is always a need for a moderator in conferencing to stimulate conversation and watch out for trouble, etc. Berge (1995) describes the role of the moderator in computer conferencing as involving 'special technical and educational responsibilities and powers'. The role of the IMF however is different. The IMF is responsible for

(a) constructing the environment;

(b) acting as a facilitator and motivator; and

(c) encouraging tutors and students to utilize the medium in order to take full responsibility 
for their teaching and learning. In the future the IMF's role will develop across different types of media, but in this specific implementation, the IMF facilitated distance learning students' use of conferencing and the World Wide Web. The IMF, in this instance and in the future, did and would develop teaching materials to guide the students in their use of new technology, in this case to bring them online. The IMF was the overall controller or administrator for all conferences (including social conferences), and guided the tutors and students in how to use the system for teaching and learning. Tutors and students have varying levels of experience in, and abilities at, mastering new technology, and the IMF needed to encourage the learner not to be frightened of the technology. This was achieved partly by monitoring and encouraging activity in all conferences relevant to the course, directing the students to the different conferences at the right time, setting up new conferences and access permission as required.

The IMF looked out for developing needs for conferences, sent encouraging personal messages to the students and tutors, and kept a watchful overview to spot problems before they arose. The IMF was centrally based and the lynch pin (contact person) for students and tutors alike to contact when they first came onto the system and in cases of problems throughout the year. We would recommend that in the future the IMF might be seen as part of the course team (that is, part of the group of people putting together the distance-learning course), taking overall responsibility for the online side of course production, that is, preparing relevant documentation to enable the students to access the facilities, and then following the role through to creating the environment and facilitating the tutor and student participation. In this way, the IMF would be aware of the learning aims of the course, while supplying expertise in how the technology could be used to meet objectives in both the design and presentation of the course. The use of new technology would therefore be integral to the course and not just a bolton after-thought. The IMF could take control of a number of courses, but work overload must be avoided if the IMF is to fulfil all his or her duties.

\section{STILE participants}

Of the 110 students taking part, 24 were female and 86 were male. Of the 24 female students, nine had used a modem before, and 15 had not. Six of the female students had used conferencing software, and one had used Internet mail. Of the 86 male students, 50 had experience of using a modem, and 36 did not. Sixteen of the male students had experience of using conferencing software, and 15 had experience of sending Internet mail. The gender of the nine tutors taking part in M205-STILE was six males to three females. One of the tutors had previous experience in conferencing. Two had experience of using modems. Six had varying experience in using email. All used computers as part of tutoring M205, and all used computers for their occupation.

\section{Preliminary findings}

The presentation of the course runs from February through to October, and requires the students to submit eight tutor-marked assignments and to sit an examination at the end of the course. To gauge what type of activity the students were involved in and how it changed, we have analysed the number and type of messages in two sub-conferences, which were the Meeting Place, a social conference, and M205-Help, a work-focused conference. The period 


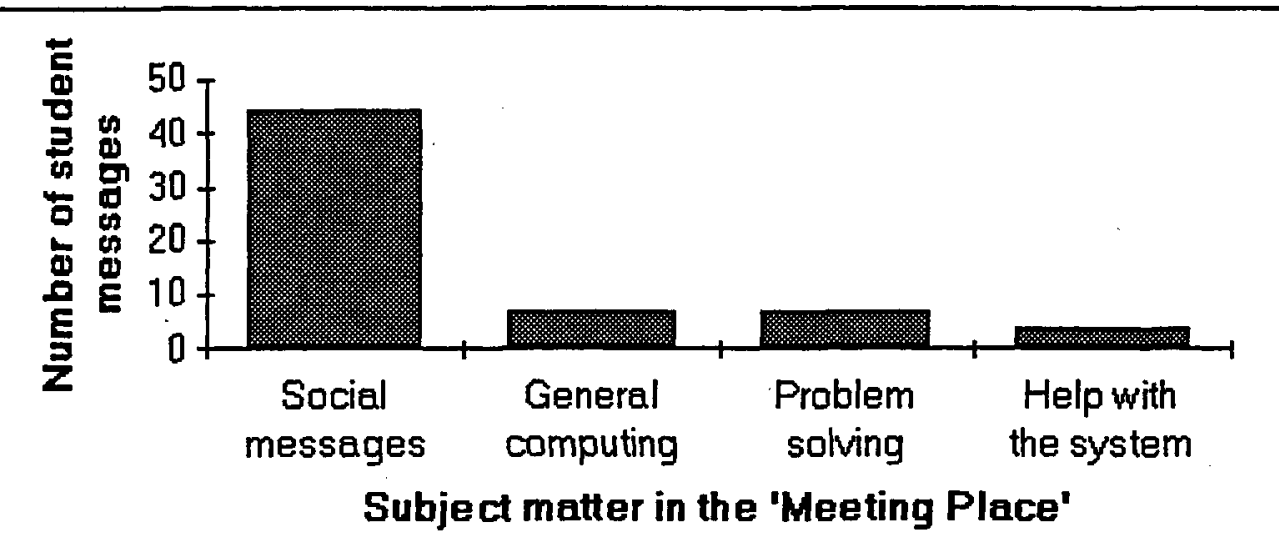

Figure 2: Type of messages found in the Meeting Place

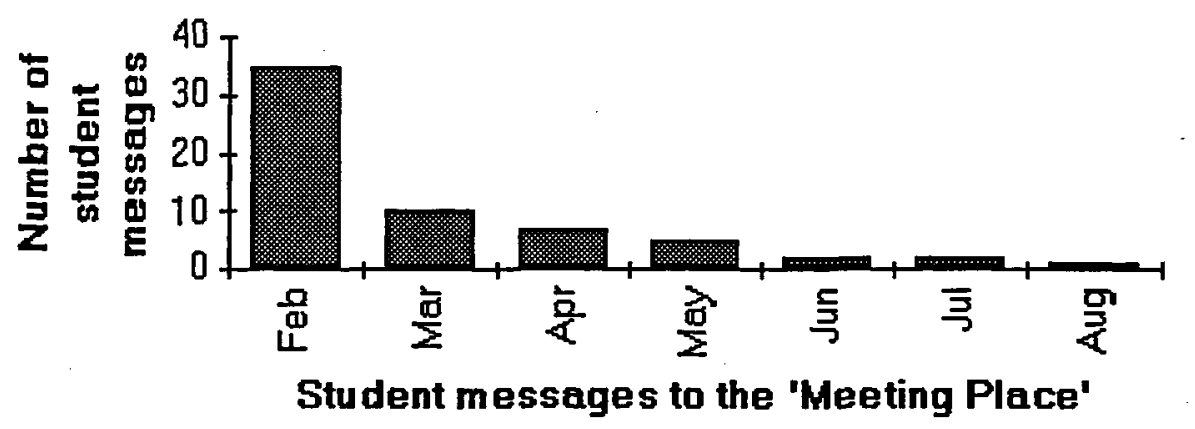

Figure 3: Number of student messages posted to the Meeting Place per month

monitored was between February and August, 1995. These two conferences were compared since there was no restriction on who could access either conference.

\section{Social aspects}

The social dimension of the conference was apparent from the beginning, since we found that students tried to get to know the system, and in so doing started to learn about each other. The first month was a critical period for social activity before the focus on course-content became more important. Looking at the social conference, that is the Meeting Place, the majority of student messages are for fellow students. Not much talk is directed to their tutor. Student messages to their fellow students accounted for $47.6 \%$ of messages, while student messages to tutors only accounted for $5.6 \%$. There is very little talk about general computing, problemsolving or about help with the system itself; in fact, as one would expect, most of the messages were of the 'getting to know you' type (see Figure 2).

The pattern of student interaction from February to August in the Meeting Place is shown in 
Figure 3. More messages were recorded in February, while there was only one in August. This suggests that in the first month the students were using the system from the earliest opportunity to make contact with each other and their tutor. There was no need to talk about work at this stage, and we found that students discussed work-related issues later in the course (see below, 'Knowledge dimension').

Students introduced themselves to each other in a number of different ways, but a typical early social message is illustrated by the following example.

8 Feb

Hello everyone,

I have been having fun working my way around the icons!

I'm from Barry so perhaps I'm within yelling distance of Merthyr!!

Anyone else in the $S$. Wales area about?

Good luck everyone. Happy clicking!

\section{Knowledge dimension}

The M205-Help conference was an area set aside specifically for daily help with solving computing problems. Members of the course team who originally wrote the course material were available here to answer queries. The tutors were also invited to 'chip in' if they could. The majority of messages in this area were student-to-student interaction. Very little talk was directed to the course team or tutor (see Figure 4). A message-approval feature was available with the software but was not adopted in either this conference or the Meeting Place conference. This meant that whatever message a student put up, the other students could see it immediately and respond without waiting for the course team to reply. Whether the messageapproval feature was used or not could have a great bearing on the flow of messages. Some students have reported frustration with other conferences when new messages were posted but not readable because they had not been approved.

Of the total number of messages in this conference, $69 \%$ were generated by the students themselves. Again the majority of student messages were for their fellow students, rather than the tutors. Student messages to their fellow students accounted for $56.8 \%$ of messages, while student messages to tutors only accounted for $7.2 \%$. When the message content was analysed (see Figure 4), there were more messages of a problem-solving nature than about using the system, etc. The M205-Help conference had been designed as a problem-solving area. The IMF sent messages to encourage the students to use this conference to ask the course team and their fellow students for help.

When the messages from the M205-Help conference were analyzed over time (February to August - see Figure 5), very few messages were found for the month of February. Our data indicates that there was more activity in The Meeting Place during this first month (see below, 'Social aspects'). Since the messages there were more like introductions, we would suggest that the students at this time were busy getting to know each other and the system rather than solving computing problems. The number of messages, however, increased in the M205-Help conference for the month of March, and remained steady through April, May and June. In July, the number of messages increased, and this could be explained by the fact that the students needed to submit a tutor-marked assignment by 1 August. Upon closer inspection of the nature 


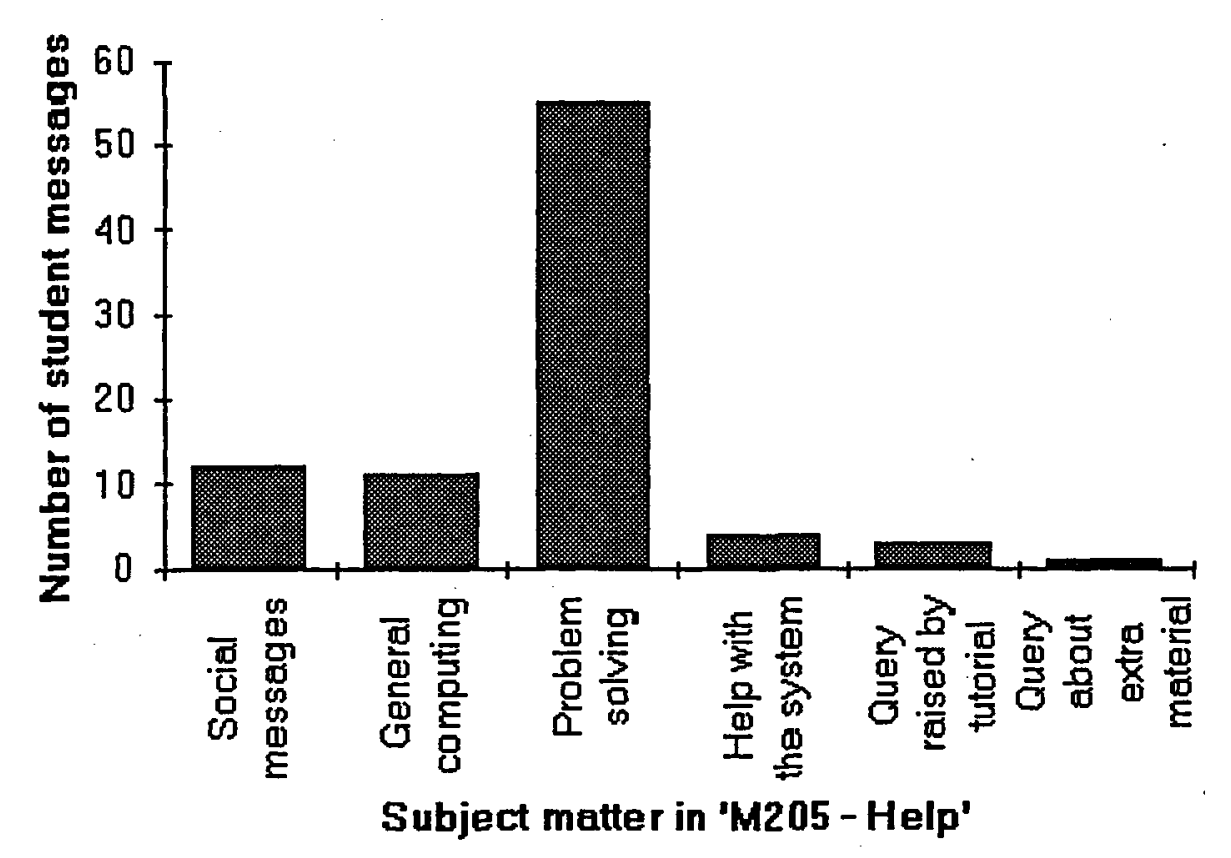

Figure 4: Type of messages found in M205-Help

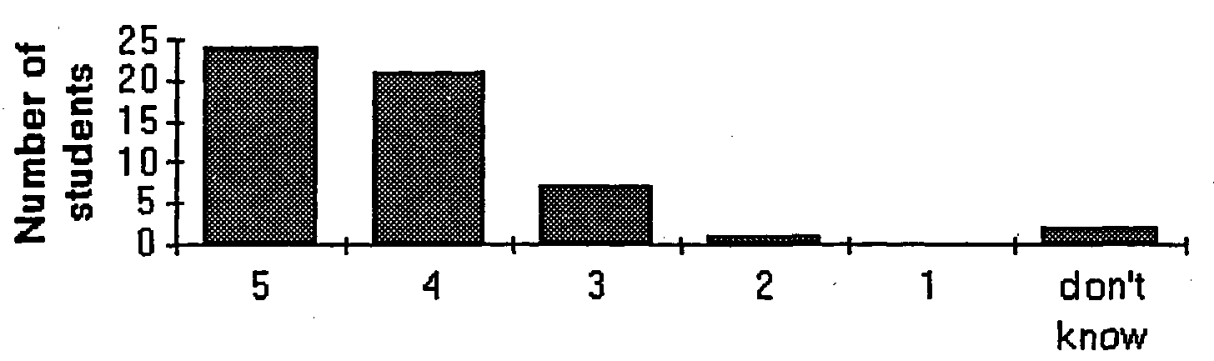

Scale of 1 to 5. 5=very interested

Figure 5: Number of student messoges posted to M205-Help per month

of the message content, students were asking each other for help with respect to these assignments.

The majority of messages in the M205-Help conference were related to students aiding each other with specific problems which could be conceptualized, as shown in the first message below, or as technical problems - see message of 9 April. 
8 April

Hi Andie

from your reply you still seem a bit confused about how to use the two arrays 'previous' and 'newreadings'. I apologise if this is not the case but if it is, then here is another hint. When you get your electricity bill at home, you get charged for the units used. That is the difference between the previous reading and the new reading.

\section{April}

You can also save the files you want to keep to a floppy (zero the volume and then rescan volumes so you get it up in your (ist), then you can just delete the file off of your user volume.

\section{Motivational aspects}

The role of the IMF was envisaged as sustaining student motivation throughout the duration of the course by responding quickly and effectively to students needs. The students were instructed to direct their subject specific issues to their own tutor's tutorial conference or to the M205-Help conference. In the latter, they could expect help from their fellow students and three members of the course team. However, we have found that the IMF has been asked about specific help with programming difficulties as well as technical problems with operating the CMC. A further role also emerged, that of counsellor. As a case in point, the IMF was asked about his competence as a Pascal programmer, and in the ensuing conversation it became evident that the student was struggling on from one tutor-marked assignment to the next, continually reflecting on 'should he stay on the course'. In fact, this student and others have stated that they would have abandoned the course if M205-STILE was not providing support for their study. With M205-STILE, they felt they could see whether other students were experiencing the same difficulties as themselves. One such student has developed a learning strategy whereby he follows the questions asked by another student who orchestrated the difficulties. In effect, he was shadowing the other student and relying on the latter to obtain essential information for his own understanding. The students also expressed their belief in the conferencing system to provide pertinent help, and hence sustain their motivation and interest:

$13 \mathrm{Feb}$

\section{Hi George,}

From the Aberdeen area. I'm looking forward to the course and am all in favour of this type of contact with other students and the tutor. Hopefully I will not need to use this method of communication with you too often (wishful thinking i.e. the course is easy) but if I do then I'm sure that I can say what I'm stuck with more clearly via e-mail than over the telephone. And I won't hesitate to use this method.

At the beginning of the course, all of the students were sent a questionnaire about how interested they were in using M205-STILE to help their study. A response rate of 50\% was obtained, and the majority of students who replied felt motivated to use the system to aid their understanding of the computing subject matter (see Figure 6). 


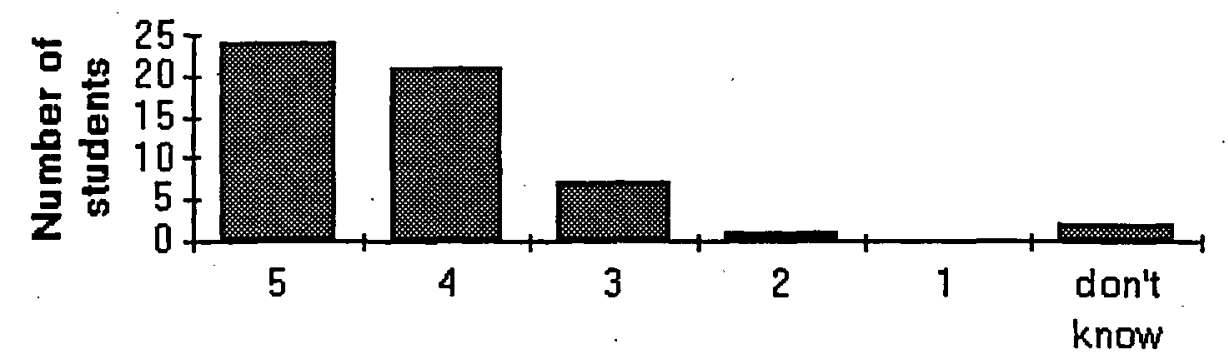

Scale of 1 to 5 . 5=very interested

Figure 6: Students' interest in using the system at the beginning of the project

\section{Summary of findings}

Our preliminary findings suggest that the conferences were being used to explore coursecontent, although some social 'chit-chat' still took place. Many students have been looking on from the sidelines, i.e. not leaving messages, but evidence from student comments suggest that they have found it very helpful to watch the question-and-answer sessions, for example in the M205-Help conference approximately five questions per week were asked, but approximately 35 students read each of these messages. Students were using the system to find out what happened at any face-to-face tutorial they missed, and were also obtaining help with their M205 coursework.

Although the tutorial conferences are not discussed in detail here, some were busier than others. Students have reported that they have found it very helpful to have read-only access to all the tutorials apart from their own. It will be interesting to see in a later analysis if the tutorial conferences are used more for work-related dialogue as the course gets progressively harder.

\section{Planned follow-up}

One important finding to date has been that the tutors were not complaining of being overloaded with student messages, and follow-up studies will involve discussing with the tutors the effectiveness of the conference structure and how the role of the IMF reduced their perceived workload. The students were very interested in using M205-STILE in the early part of the course; a follow-up survey to be conducted in December will indicate how well they were motivated to use the system throughout the presentation of the course, and especially for their revision.

\section{Conclusions}

This paper proposed that student interactions while using a CMC could be monitored in the three dimensions summarized in our introduction: a knowledge dimension (which includes domain and meta-knowledge), a social dimension, and a motivational dimension. 
By comparing the social and help conferences (see Figures 2, 3,4 and 5), it can be seen that the social dimension was more important at the beginning. The critical period for the students to get to know each other and the system was one month. Only then did they make use of the system for their coursework. It can be seen that use along the knowledge dimension then increased. Although specific conference areas, for example M205-Help and the tutorial conferences, were set up to deal with domain-specific interactions, the numbers of messages were deceptively small. This was due to the fact that more students were reading the messages rather than generating their own messages. Students said that because they had read-only access to all tutorials, they were obtaining enough information about their assignments by scanning all the messages. Although only five or six messages were posted per week to the M205-Help conference, these messages were, surprisingly, read by more than 30 students. The motivational dimension became apparent from the students' enthusiasm to use M205-STILE to aid their study not only to describe their problems but also to read messages left by other students.

M205-STILE was set up to minimize information overload for both tutors and students. An important factor could be the IMF's overall responsibility for designing the conference and sub-conference structure and guiding the tutor and student activity without intervening too much. The IMF designed conference areas to promote work-related dialogue, and to encourage the students to help each other in a supervised environment. The latter point is important because without expert computer-science onlookers, the students could have confused each other. The IMF also played a role in promoting work-related dialogue by responding quickly to student problems with the technology itself.

\section{Acknowledgements}

The research described in this paper was undertaken in the Computing Department, Faculty of Mathematics and Computing at the Open University, as part of the STILE project. The project was supported by a grant from the Teaching and Learning Technology Programme (TLTP).

\section{References}

Berge, Z. L. (1995), 'Facilitating computer conferencing: recommendations from the field', Educational Technology, 35 (1).

Goodyear, P. and Steeples, C. (1994), 'Computer-mediated communication in the professional development of workers in the advanced learning technologies industry' in Eccleston, J., Barta, B. and Hambusch, R. (eds), The Computer-Mediated Education of Information Technology Professionals and Advanced End-Users, Amsterdam, Elsevier.

Goodyear, P., Johnson, R. and Steeples, C. (1991), 'Training of courseware designers at a distance', Proceedings of 8th International Conference on Technology and Education, Toronto.

Mason, R. and Kaye, A. (1989), Mindweave, Oxford, Pergamon Press.

Mayes, T., Coventry, L., Thomson, A. and Mason, R. (1994), 'Learning through Telematics. A Learning Framework for Telecommunication Applications in Higher Education', The Institute for Computer Based Learning and The Open University, Report ref. E31/E33 for British Telecom. 
Shedletsky, L. (1993), 'Minding computer-mediated communication: CMC as experiential learning', Educational Technology, 23 (12).

Steeples, C., Goodyear, P. and Mellar, H. (1993), 'Flexible learning in higher education : the use of computer-mediated communications', Computers and Education, Oxford, Pergamon Press.

Velayo, R. S. (1994), 'Supplementary classroom instruction via computer conferencing', Educational Technology, 34 (5).

Wilson, T. (1995), Are You Able to Take Part or Not? Selecting Tutors and Students for the M205-STILE Project, internal Computing Department report for the Open University, Technical Report no. 95/08. 